\title{
Genetic Evaluation for the Proposed role of Staphylococcus aureus in Burn Patients
}

\author{
Fawziya Shareef Abed ${ }^{1}$, Saad Salman Hamim² \\ ${ }^{1}$ Scholar Researcher, ${ }^{2}$ Prof. Dr. Department of Pathological Analysis, College of Science, University of Thi-Qar, \\ Iraq
}

\begin{abstract}
Background: Staphylococcus aureus is a gram-positive spherical bacterium. It is a human skin and respiratory flora which is considered as one of the most common cause of burn infections. It always finds a way to resist antibiotics due to that it had virulence and resistance genes as well as acquired of new genes from other strains which makes it more dangerous. Aims: This study aims at investigating the prevalence of genetic evaluations for Staphylococcus aureus in the burn unit. Methods: A total of 223 burn swabs were collected from the burn patient's unit during the period from September to December 2019 in ALHussain Teaching Hospital in AL-Nasiriya City, Southern of Iraq. These 223 burn swabs were subjected to macroscopic, microscopic, cultures, biochemical test and out of the 223 clinical swab only (70) undergoes the PCR and DNA sequence technique looking for new emergence strains. Results: The current study used partial 16SrRNA gene sequences for (6) Staphylococcus aureus isolates and found (5) of them were global and one was local according to the accession numbers of NCBI Gene bank, MT605440.1, MT605441.1, MT605442.1, MT605445.1, MT605443.1, MT605444.1.
\end{abstract}

Keyword: genetic evaluations, Staphylococcus aureus, Infections-Macrolides resistance.

\section{Introduction}

Burns are a common type of injury among people. They can occur anywhere from a household setting where heat, electricity and friction might be the source of injury to industrial settings where radiation and chemical agents might be the main source of injury ${ }^{(1)}$. Burns that effect and cause trauma to the superficial layer of skin, superficial but partial thickness and a full-thickness classified as the first, second, third and fourth degree burns ${ }^{(2)}$. The skin can be exposed to a mechanical disruption by the burns injury that causes losing a part or whole of skin, since the skin acts as a protective barrier against many microorganisms and environmental conditions ${ }^{(3)}$. This loss of skin enables the human flora, environmental microbes and other pathogenic microorganisms to invade the burned area

\section{Corresponding author:}

Saad Salman Hamim

Email: hamim_pa@sci.utq.edu.iq of burn patients to reach the deeper tissues and become colonized with microorganisms ${ }^{(4)}$.

Staphylococcus aureus is the most important pathogen in the burns unit which can take the opportunity to colonize the burn wound which are a normal human flora present in the skin and respiratory tract. Nowadays, Methicillin-resistant Staph. aureus (MRSA) also resistant to a broad spectrum of antibiotics, that is considered as a serious nosocomial pathogen in burn unit due to multidrug resistance and its outbreak potential ${ }^{(5)}$. Mec A and hlb genes were carried on chromosomes ${ }^{(6)}$. While erm A, erm B and etb gene carried on plasmid which it can easily move from one strain to another, and it has an important role in their virulence, resistance and bacterial pathogenicity ${ }^{(7)}$.

\section{Material and Methods}

A total of 223 burn swabs were collected from the burn patient's unit during the period from September to December 2019 in AL-Hussain Teaching Hospital in AL-Nasiriya City, Southern of Iraq. All samples were 
collected under available sterile conditions via transportswab media and then directly transported to the laboratory to perform microscopy, culture, and sensitivity analysis. A formula was prepared for all patients, including sample number, name, date, age, gender and residence. Using both PCR and DNA sequence technique.

\section{Statistical Analysis}

All data of the present study were statistically analyzed by using Microsoft windows 10 Excel (version2010) and SPSS version 24 (ANOVA for Leas Significant Difference LSD and Independent T. test).

\section{Results}

Out of total (223) clinical sample (201) were positive and (22) $9.87 \%$ were negative, (70) $31.40 \%$ represented by Staph. aureus followed by Pseudomonas. Spp and then Enterococcus. Spp have been had a second and the third percentage respectively $29.60 \%$ and $12.55 \%$, while Escherichia coli were got the lowest percentage $0.44 \%$, and the remained percentage for other types of bacteria. According to age groups and gender the result shown in both (Tables1 \& 2) All (70) isolates of Staph. aureus bacteria were subjected to antibiotic sensitivity the results showed in (figure1). The isolate designated as multidrug-resistant (MDR), (24) 34.28\% were extensively drug-resistant (XDR) and only (2) $2.85 \%$ isolates were pan-drug-resistant (PDR). There were statistically significant differences in Antibiotics susceptibility against Staph. aureus $(\mathrm{P}>0.01)$.

Molecular result explains in (figure 2) There were statistically significant differences in gene frequency of Staph. aureus according to gene number $(\mathrm{P}>0.01)$.

Table (1): Distribution of patients according to age group and bacterial type.

\begin{tabular}{|c|c|c|c|c|c|c|}
\hline \multirow{2}{*}{$\begin{array}{c}\text { Bacteria } \\
\text { Age group (year) }\end{array}$} & \multicolumn{2}{|c|}{ Staph. aureus } & \multicolumn{2}{c|}{ Other bacteria } & \multicolumn{2}{c|}{ Total } \\
\cline { 2 - 7 } & No. & $\%$ & No. & $\%$ & No. & $\%$ \\
\hline $1-15$ & 12 & 6.6 & 11 & 6.1 & 23 & 12.7 \\
\hline $16-31$ & 24 & 13.3 & 57 & 31.5 & 81 & 44.8 \\
\hline$>31$ & 26 & 14.4 & 51 & 28.2 & 77 & 42.5 \\
\hline Total & 62 & 34.3 & 119 & 65.7 & 181 & 100 \\
\hline Cal. $\chi 2: 4.057$ & \multicolumn{2}{|c|}{ Tab. $\chi 2: 9.21$} & df:2 & & P $>0.01$ \\
\hline
\end{tabular}

Table (2): Distribution of patients according to gender.

\begin{tabular}{|c|c|c|c|c|c|c|}
\hline \multirow{2}{*}{$\begin{array}{c}\text { Gender } \\
\text { Bacteria }\end{array}$} & \multicolumn{2}{|c|}{ Male } & \multicolumn{2}{c|}{ Female } & \multicolumn{2}{c|}{ Total } \\
\cline { 2 - 7 } & No. & $\%$ & No. & $\%$ & No. & $\%$ \\
\hline Staph. aureus & 27 & 14.9 & 35 & 19.3 & 62 & 34.3 \\
\hline Other bacteria & 64 & 35.4 & 55 & 30.4 & 119 & 65.7 \\
\hline Total & 91 & 50.3 & 90 & 49.7 & 181 & 100 \\
\hline Cal.X2: 1.707 & \multicolumn{2}{|c|}{ Tab.X2:6.63 } & & df: 1 & \multicolumn{2}{c|}{ P_value: $0.01^{2}$} \\
\hline
\end{tabular}




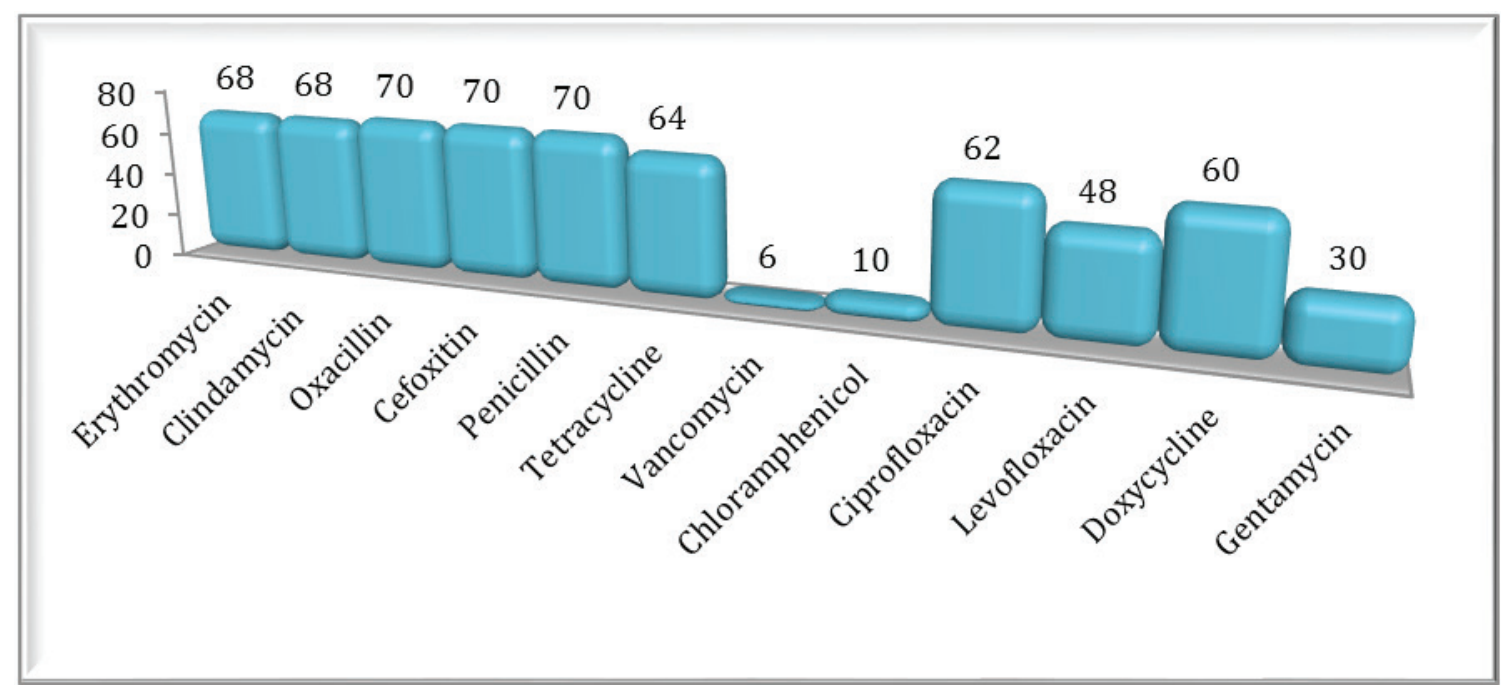

Cal.X ${ }^{2}$ : 526.72 Tab.X ${ }^{2}: 33.92$ df:22 p-value:0.01

(Figure 1): Antibiotics susceptibility against Staph. aureus bacteria.

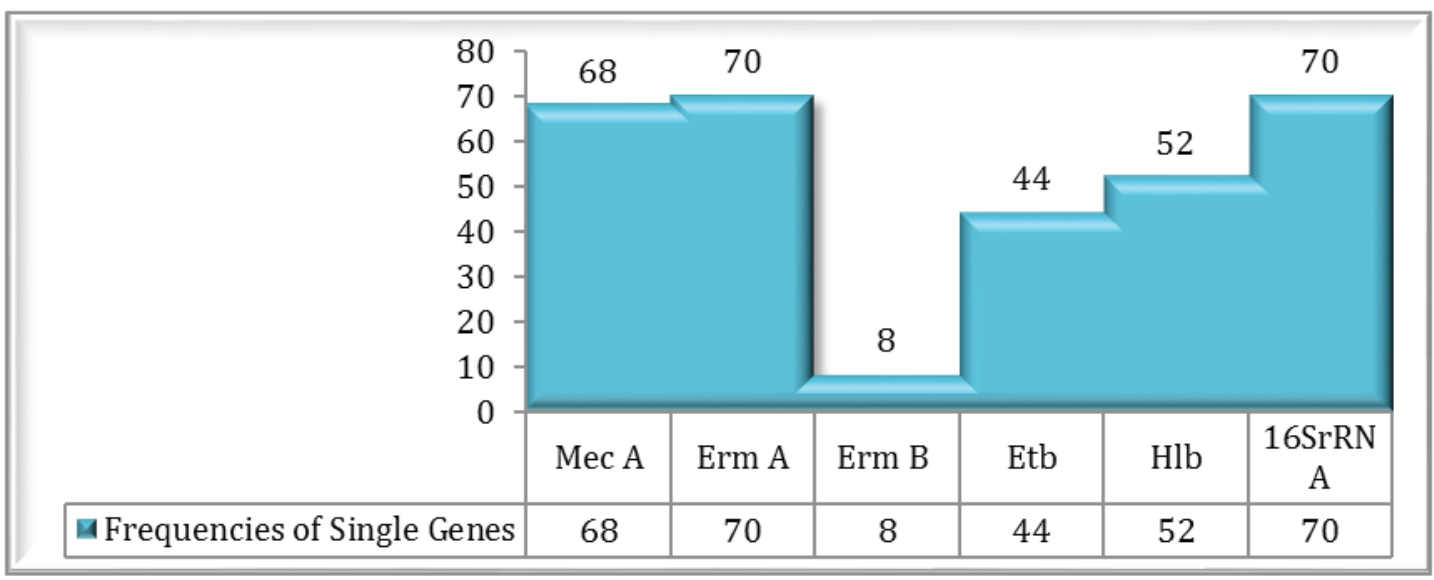

Cal.X 2 : $55.84 \quad$ Tab.X $X^{2}: 9.49$ df:5 p-value:0.01

Figure 2: Frequencies of single gene in isolated Staph. aureus.

\section{Discussion}

Bacterial identification and distribution of patients according to age group and gender

In the present time the burn wound infections become as one of the most important public health worldwide problem due to its potentially serious complication that happened approximately after injury (8). The current study revealed that Staphylococcus aureus is the predominant pathogen in burn unit followed by Pseudomonas. This study was consistent with the local study in Iraq provided by Spp which concluded that (66) out of (80) Staph. aureus was the predominant bacteria $(33.33 \%)$ followed by Pseudomonas Spp $(31.81 \%)^{(9)}$. According to age group, the results of the current study recorded that the higher patients infected with infectious bacteria was in the second age group whereas the first age group was recorded as the lowest percentage. Hence, the third age group recorded the highest group infected with Staph. aureus, as that agreed with finding reported by ${ }^{(10)}$ who provided that $16-30$ age group had the highest percentage. In contrast, (11), his study revealed that burn injuries were significantly common among young age group less than 20 years ( 70 . $4 \%$ ). The third age group in the current study was the most infected with Staph. aureus may be due to their age who susceptible to many compromised factors that made them more susceptible to Staph. aureus ${ }^{(12)}$. The reason behind these differences might be due to that the 
second age group (16-30) years is most active in doing cooking, driving, etc. but also most of it was due to suicides (by burning) as what I noticed during my study. Also the elderly and new-born those who are immune suppressed Particular groups at higher risk exposure to Staph. aureus infection. According to gender, males are more exposure to infection than females whereas female recorded the higher most patients infected with Staph. aureus as that agreed with this study ${ }^{(13)}$, Ethiopia, from 114 burn patients were males' infection 58(50.9\%) more than females 56(49.1\%) also the females recorded the most infected patient with Staph. aureus 35(53.0) while the males got the percentage 31(47.0) rather than female. This may be due to that the males are exposed to burns as they driving cars, wearing a combustible clothes. In my country males may be affected more due to their presence as revolutionaries whom they were exposed to a very hot water by suppression of the authority. In the case of females were more likely exposed to Staph. aureus due to contamination as it appears in my result or due to other unknown reasons.

\section{Antibiotics susceptibility and Molecular Identification}

The current study of the antibiotic susceptibility for Staph. aureus its 100\% resistance against Oxacillin, Cefoxitin and penicillin was consistent with the local study in Iraq provided by ${ }^{(20)}$. But, my results showed the beginning of an almost complete resistance against some of macrolides and aminoglycosides respectively Erythromycin, clindamycin and Tetracycline in contrast to last study that considered they were not resistance. My subsequent results were corroborated completely with other researcher from the same country which carried out by ${ }^{(14)}$, also they agreed with me by the sensitivity test my results showed that the bacteria are more sensitive to the following antibiotics such as Vancomycin and Chloramphenicol as in his results, and that is also deals with study outside the country provided by ${ }^{(15)}$, Iran, deals with my result in both the resistance and sensitivity to the previous antibiotics. Despite the development of control and prevention methods, challenges in the treatment of staphylococcal infections are accompanied by several mechanisms such as biofilm formation in this bacterium enzymes production such as beta lactamase ${ }^{(16)}$, and also the misuse and overuse of some antibiotics ${ }^{(15)}$. My own opinion, in additions to the previous reasons it is may be due to the contamination in and around the burn unit, including the staff and other than that, led to the formation of new resistance genes, the current study shows $100 \%$ resistance to $\mathrm{Mec}$ A gene and erm A gene and the appearance of new strains that possess a lot of etb gene in Iraq, all these conditions are responsible for the appearance of more new dangerous mergence strains.

The current study showed that all (70) of Staph. aureus isolates were positive $100 \%$ for 16 SrRNA and $\mathrm{Mec} \mathrm{A}$ gene that the results showed almost semi complete percentage. As that's agreed with the local study provided by ${ }^{(17)}$, in Iraq, they found all 96 Staph. aureus isolates $100 \%$ positive that were identified by PCR. Also that is agreed with study worldwide carried out by ${ }^{(18)}$. Local study carried out by ${ }^{(19)}$. In Iraq out of 140 Staph. aureus isolates 113 bacterial isolate were MRSA. Also my result deals with this study which provided by ${ }^{(20)}$, Iran, all burn swab were positive to $\mathrm{Mec}$ A gene. Detection of both erm A and erm B gene in Staph. aureus, I could not find this percentage in my country, perhaps it is due to no one act on these genes in burn unit. Worldwide, the current study disagreed with this study provided by ${ }^{(21)}$, they show that the percentage against macrolides in burn patients, the prevalence of both erm A and erm B, 11\% (19/170) and 3.5\% (6/170) respectively. My study agreed with study carried out by ${ }^{(22)}$, they found that erm A is the predominant, and the resistance rate. For $e t b$ and $h l b$ Genes, all previous studies have been proven that etb gene is not present, or present in a small quantities in both our country and worldwide as that deals with local study in Iraq provided by (19), their sources showed that this gene is not available in Iraq before, so they found that out of (113) clinical isolates $5.31 \%$ have a positive results for $e t b$ gene, this also corresponds to other international studies In a Turkish study done by ${ }^{(23)}$, detected none $e t b$ toxin gene, it is absence, in the United States the study carried out by ${ }^{(24)}$, the frequency range of etb gene in MRSA was $0-22 \%$, and this is terrible compared to ( $62.58 \%$ ) rates out of 70 samples as that indicated by the current study. For $h l b$ gene I agreed with local study from Iraq provided by (25), as well as my results disagree with next study whom showed that no one of (MRSA) strains carry the $(h l b)$ gene which carried out by ${ }^{(26)}$. 


\section{Conclusion}

There were high rates of burn infections due to Staphylococcus aureus resistance to many antibiotics. Thus infections cannot be easily controlled due to various virulence factors and resistance gene which most of them carried on plasmids that mediate the appearance of new resistance strains. Also for the investigation of antibiotic resistance may provide crucial information about the control of such infections so it will be necessary to accurately identify antibiotic resistance on routine susceptibility tests.

\section{Conflict of Interest: None}

\section{Funding: Self}

Ethical Clearance: Not required

\section{References}

1. Poon, C. S. Early assessment of burn severity in human tissue with multi-wavelength spatial frequency domain imaging, 2016.pp.13.

2. Jeschke, M. G., Pinto, R., Kraft, R., Nathens, A. B., Finnerty, C. C., Gamelli, R. L., ... \& Herndon, D. N. Morbidity and survival probability in burn patients in modern burn care. Critical care Critical care medicine, 2015. 43(4), page 808-815.

3. Sharma, B. R. Infection in patients with severe burns: causes and prevention thereof. Infectious disease clinics of North America, 2007. 21(3), 745759.

4. Panghal, M., Singh, K., Kadyan, S., Chaudary, U., \& Yadav, J. P. The analysis of distribution of multidrug resistant Pseudomonas and Bacillus species from burn patients and burn ward environment. Burns, 2015. 41(4), 812-819.

5. Barbut, F., Yezli, S., Mimoun, M., Pham, J., Chaouat, M., \& Otter, J. A. Reducing the spread of Acinetobacter baumannii and methicillin-resistant Staphylococcus aureus on a burns unit through the intervention of an infection control bundle. Burns, 2013. 39(3), 395-403.

6. Yoon, E. J., Lee, H., Kim, D., Shin, J. H., Shin, J. H., \& Jeong, S. H. MethicillinResistant Staphylococcus aureus Blood Isolates Harboring a Novel Pseudo-staphylococcal Cassette Chromosome mec Element. Frontiers in microbiology, 2019. 10, 540.

7. Asanin, J., Misic, D., Aksentijevic, K., Tambur, Z., Rakonjac, B., Kovacevic, I., Spergser, J., \& Loncaric, I. Genetic Profiling and Comparison of Human and Animal Methicillin-Resistant Staphylococcus aureus (MRSA) Isolates from Serbia. Antibiotics (Basel, Switzerland), 2019. 8(1), 26.

8. Rafla, K., \& Tredget, E. E. Infection control in the burn unit. Burns, 2011.37(1), 5.9

9. Al-Byti, A. M., Chakmakchy, S. A., Waheeb, A. A., \& Alazzawy, M. A. Study of Isolated Bacteria from Burn Wound of Patients Attended Plastic Surgery and Burns Unit. Indian Journal of Forensic Medicine \& Toxicology, 2019. 13(4), 1462-1466.

10. Taneja, N., Emmanuel, R., Chari, P. S., \& Sharma, M. A prospective study of hospital-acquired infections in burn patients at a tertiary care referral centre in North India. Burns, 2004. 30(7), 665-669.

11. Melake, N. A., Eissa, N. A., Keshk, T. F., \& Sleem, A. S. Prevalence of multidrug-resistant bacteria isolated from patients with burn infection. Menoufia Medical Journal, 2015. 28(3), 677-684.

12. Alebachew, T., Yismaw, G., Derabe, A., \& Sisay, Z. Staphylococcus aureus burn wound infection among patients attending Yekatit 12 hospital burn unit, Addis Ababa, Ethiopia. Ethiopian journalof health sciences, 2012. 22(3) page209-13.

13. Aljanaby, A. A. J., \& Aljanaby, I. A. J. Prevalence of aerobic pathogenic bacteria isolated from patients with burn infection and their antimicrobial susceptibility patterns in Al-NajafCity, Iraq-a threeyear cross-sectional study. F1000Research, 2018. 7(1157), page 1-14.

14. Othman, N., Babakir-Mina, M., Noori, C. K., \& Rashid, P. Y. Pseudomonas aeruginosa infection in burn patients in Sulaimaniyah, Iraq: risk factors and antibiotic resistance rates. The Journal of Infection in Developing Countries, 2014. 8(11), 1498-1502.

15. Moghadam, S. O., Pourmand, M. R., \& Aminharati, F. Biofilm formation and antimicrobial resistance in methicillin-resistant Staphylococcus aureus isolated from burn patients, Iran. The Journal of Infection in Developing Countries, 2014. 8(12), 1511-1517. 
16. Moghadam, Solmaz Ohadian, Mohammad Reza Pourmand, and Farzaneh Aminharati. "Biofilm formation and antimicrobial resistance in methicillin-resistant Staphylococcus aureus isolated from burn patients, Iran." The Journal of Infection in Developing Countries 2014. 8.12: 1511-1517.

17. Shamkhi, G. J., Saadedin, S. M., \& Jassim, K. A. Detection the Prevalence of Some Chromosomal Efflux Pump Genes in Methicillin Resistant Staphylococcus aureus Isolated from Iraqi Patients. Iraqi journal of biotechnology, 2019. 18(3) page 33-42.7

18. Montazeri, E. A., Khosravi, A. D., Jolodar, A., Ghaderpanah, M., \& Azarpira, S. Identification of methicillin-resistant Staphylococcus aureus (MRSA) strains isolated from burn patients by multiplex PCR. Burns, 2015. 41(3), 590-594.

19. Saleem, A. J., Nasser, N. E., \& Ali, M. R. Prevalence of genes encoding enterotoxins and exfoliative toxins among methicillin resistant Staphylococcus aureus clinical isolates in Iraq. World Journal of Pharmaceutical Research, 2016. 5(7), 208-16.

20. Goudarzi, M., Bahramian, M., Tabrizi, M. S., Udo, E. E., Figueiredo, A. M. S., Fazeli, M., \& Goudarzi, H. Genetic diversity of methicillin resistant Staphylococcus aureus strains isolated from burn patients in Iran: ST239-SCCmec III/t037 emerges as the major clone. Microbial pathogenesis, 2017. 105, 1-7.'

21. Fasihi, Y., Saffari, F., Kandehkar Ghahraman, M. R., \& Kalantar-Neyestanaki, D. Molecular detection of macrolide and lincosamide-resistance genes in clinical methicillin-resistant Staphylococcus aureus isolates from Kerman, Iran. Arch Pediatr Infect Dis, 2017. 5(1), e37761.

22. Shahsavan, S., Emaneini, M., Khoshgnab, B. N., Khoramian, B., Asadollahi, P., Aligholi, M. \& Taherikalani, M. A high prevalence of mupirocin and macrolide resistance determinant among Staphylococcus aureus strains isolated from burnt patients. Burns, 2012. 38(3), 378-382.ๆ

23. Dağı, H. T., Fındık, D., Demirel, G., \& Arslan, $\mathrm{U}$. Detection of methicillin resistance and various virulence factors in Staphylococcus aureus strains isolated from nasal carriers. Balkan Medical Journal, 2015. 32(2), page 171-175.

24. Shukla, S. K., Karow, M. E., Brady, J. M., Stemper, M. E., Kislow, J., Moore, N., ... \& Lynfield, R. Virulence genes and genotypic associations in nasal carriage, community-associated methicillinsusceptible and methicillin-resistant USA400 Staphylococcus aureus isolates. Journal of clinical microbiology, 2010. 48(10), 1-17.

25. Degaim, Z. D., Shani, W. S., \& Hamim, S. S. Virulence factors of Methicillin Resistant Staphylococcus aureus (MRSA) isolated from burn patients. Inter J Curr Microbiol Appl Sci, 2015. 4, 898-906. 9

26. Motallebi, M., Jabalameli, F., Asadollahi, K., Taherikalani, M., \& Emaneini, M. Spreading of genes encoding enterotoxins, haemolysins, adhesin and biofilm among methicillin resistant Staphylococcus aureus strains with staphylococcal cassette chromosome mec type IIIA isolated from burn patients. Microbial pathogenesis, 2016. 97, 34-37. 